\title{
ASSESSMENT OF EXTERNAL HEAT TRANSFER MODELING OF A LABORATORY-SCALE COMBUSTOR INSIDE A PRESSURE-HOUSING ENVIRONMENT
}

\author{
P. Rodrigues ${ }^{\S}$, O. Gicquel ${ }^{\S}$, N. Darabiha ${ }^{\S}$, K.P. Geigle ${ }^{\ddagger}$, R. Vicquelin ${ }^{\S}$, \\ §Laboratoire EM2C, CentraleSupélec, CNRS \\ 3 Rue Joliot Curie \\ 91192 Gif-sur-Yvette Cedex \\ France \\ ¥ German Aerospace Center (DLR) \\ Institute of Combustion Technology \\ Pfaffenwaldring 38-40 \\ 70569 Stuttgart \\ Germany
}

\begin{abstract}
Many laboratory-scale combustors are equipped with viewing windows to allow for characterization of the reactive flow. Additionally, pressure housing is used in this configuration to study confined pressurized flames. Since the flame characteristics are influenced by heat losses, the prediction of wall temperature fields becomes increasingly necessary to account for conjugate heat transfer in simulations of reactive flows. For configurations similar to this one, the pressure housing makes the use of such computations difficult in the whole system. It is therefore more appropriate to model the external heat transfer beyond the first set of quartz windows. The present study deals with the derivation of such a model which accounts for convective heat transfer from quartz windows external face cooling system, free convection on the quartz windows 2, quartz windows radiative properties, radiative transfer inside the pressure housing and heat conduction through the quartz window. The presence of semi-transparent viewing windows demands additional care in describing its effects in combustor heat transfers. Because this presence is not an issue in industrial-scale combustors with opaque enclosures, it remains hitherto unaddressed in laboratory-scale combustors. After validating the model for the selected setup, the sensitivity of several modeling choices is computed. This enables a simpler expression of the external heat transfer model that can be easily implemented in coupled simu-
\end{abstract}

\footnotetext{
*Address all correspondence to this author: pedro.rodrigues@ centraliens.net
}

lations.

\section{NOMENCLATURE}
$A_{\lambda} \quad$ External absorptance [-]
$F_{i j} \quad$ View factor [-]
Gr Grashof number [-]
I Radiative intensity $\left[\mathrm{W} / \mathrm{m}^{2} / \mathrm{sr}\right]$
$L \quad$ Height of quartz widows [m]
$\mathrm{Nu} \quad$ Nusselt number [-]
$P \quad$ Power [W]
Pr Prandtl number [-]
$R_{\lambda} \quad$ External reflectance [-]
$\mathrm{Ra} \quad$ Rayleigh number [-]
Re Reynolds number [-]
$T$ Temperature [K]
$T_{\text {film }} \quad$ Film temperature [K]




\begin{tabular}{|c|c|}
\hline$T_{\lambda}$ & External transmittance $[-]$ \\
\hline $\mathscr{F}$ & Parametrized view factor \\
\hline $\mathscr{U}, \mathscr{V}, \mathscr{U}_{1}, \mathscr{V}_{1}$ & Dimensionless length [-] \\
\hline$b$ & Distance separating quartz windows [m] \\
\hline$c_{p}$ & Heat capacity per unit mass $[\mathrm{J} / \mathrm{kg} / \mathrm{K}]$ \\
\hline$d_{\text {jet }}$ & Jet exit diameter [m] \\
\hline$e$ & Quartz slab thickness [m] \\
\hline$e_{\mathrm{eq}}$ & Equivalent thickness of wall jet $[\mathrm{m}]$ \\
\hline$g$ & Acceleration due to gravity $\left[\mathrm{m} / \mathrm{s}^{2}\right]$ \\
\hline$h$ & Heat transfer coefficient $\left[\mathrm{W} / \mathrm{m}^{2} / \mathrm{K}\right]$ \\
\hline$k$ & Thermal conductivity [W/m/K] \\
\hline$k_{\lambda}$ & Absorptive index [-] \\
\hline$l$ & Length of quartz widows [m] \\
\hline$l_{\text {th }}$ & Thermal length $[\mathrm{m}]$ \\
\hline$n_{\lambda}$ & Refractive index [-] \\
\hline$p$ & Pressure $[\mathrm{Pa}]$ \\
\hline$u$ & Velocity $[\mathrm{m} / \mathrm{s}]$ \\
\hline$x$ & Longitudinal coordinate $[\mathrm{m}]$ \\
\hline$y$ & Transverse coordinate [m] \\
\hline$z$ & Axial coordinate $[\mathrm{m}]$ \\
\hline$\alpha_{i}$ & Sensitivity parameters [-] \\
\hline$\beta$ & Thermal expansion coefficient $\left[\mathrm{K}^{-1}\right]$ \\
\hline$\varepsilon_{\lambda}$ & Internal emittance $[-]$ \\
\hline$\eta$ & Dimensionless transverse distance [-] \\
\hline$\kappa$ & Absorption coefficient $\left[\mathrm{m}^{-1}\right]$ \\
\hline$\mu$ & Dynamic viscosity $[\mathrm{kg} / \mathrm{m} / \mathrm{s}]$ \\
\hline$v$ & Kinematic viscosity $\left[\mathrm{m}^{2} / \mathrm{s}\right]$ \\
\hline$\lambda$ & Wavelength [nm] \\
\hline$\Omega$ & Solid angle [sr] \\
\hline$\Phi$ & Equivalence ratio [-] \\
\hline$\varphi$ & Thermal flux $\left[\mathrm{W} / \mathrm{m}^{2}\right]$ \\
\hline$\varphi^{\text {cond }}$ & Conductive thermal flux $\left[\mathrm{W} / \mathrm{m}^{2}\right]$ \\
\hline$\varphi^{\text {conv }}$ & Convective thermal flux $\left[\mathrm{W} / \mathrm{m}^{2}\right]$ \\
\hline$\varphi^{\text {rad }}$ & Radiative thermal flux $\left[\mathrm{W} / \mathrm{m}^{2}\right]$ \\
\hline$\rho_{\lambda}$ & Internal reflectance [-] \\
\hline$\sigma$ & Stefan-Boltzmann constant $\left[\mathrm{W} / \mathrm{m}^{2} / \mathrm{K}^{4}\right]$ \\
\hline$\tau_{\lambda}$ & Internal transmittance [-] \\
\hline air & Relative to air \\
\hline$i$ & Incident quantity \\
\hline l & Leaving quantity \\
\hline$\circ$ & Equilibrium quantity \\
\hline slab & Relative to a quartz slab \\
\hline slab,model & Relative to a modeled quartz slab \\
\hline slab,hem & Hemispherical slab averaged quantity \\
\hline $\mathrm{L}$ & Equivalent quantity over length L \\
\hline 0 & Value at $T_{0}=293 \mathrm{~K}$ \\
\hline in & Relative to inner surface of the first quartz window \\
\hline jet & Relative to air jets \\
\hline out & Relative to outer surface of the first quartz window \\
\hline threshold & Threshold value \\
\hline wjet & Relative to equivalent wall air jet \\
\hline 1 & Relative to the first quartz window \\
\hline
\end{tabular}

2a Relative to inner surface of the second quartz window

$2 \mathrm{~b}$ Relative to outer surface of the second quartz window

2 Relative to the second quartz windows

3 Relative to stainless steel pressure housing

- Averaged quantity

\section{INTRODUCTION}

In aircraft engines as in many applications, the reactive flow in the combustion chamber is both turbulent and high in pressure. Optical access to the flame is necessary to thoroughly study such configurations at a laboratory scale, while maintaining representative pressures of real applications. To do so, a pressure housing can be used in order to impose pressure within the combustion chamber [1-3], as experimentally investigated in the considered sooting turbulent ethylene/air flame at DLR [4]. This swirled turbulent non-premixed flame is stabilized at several pressures ( 1,3 and 5 bars) for several operating points inside a high pressure combustion chamber. Optical access into the combustion chamber is provided through four separate quartz windows, collectively labeled as quartz windows 1 . Cooling of the quartz windows 1 is established through multiple transverse laminar air jets on the outer face, i.e. outside of the combustion chamber. This allows for a better definition of boundary conditions inside the combustor, specifically for modeling purposes. The combustion chamber is surrounded by the stainless steel pressure housing equipped with four quartz windows (denoted quartz windows 2) for optical access to the combustion chamber. Quartz windows 1 and 2 present semi-transparent radiative properties: transparent for visible wavelengths, but opaque for infrared ones [5]. Several numerical studies have investigated this setup [6-10] without much attention to the combustor heat transfer mechanisms. However, heat losses due to wall heat transfer and radiation impact flame stabilization [11-14], gas temperature, and consequently gaseous pollutant emissions $[15,16]$ and soot production. Numerical simulations of combustors must therefore account for these heat losses either through experimental or computed boundary conditions e.g. wall temperatures on the inner windows surface. The present study aims at providing an efficient model for the corresponding combustor walls' external boundary conditions.

Using a detailed approach such as large-eddy simulation (LES) in a multiphysics framework is a promising candidate to accurately predict the wall temperature field. Such a combination of LES and conjugate heat transfer (CHT) has already been applied to several combustion applications [17-19]. When radiative energy transfer must be accounted for, the LES code is coupled to a solver of the radiative transfer equation [20-22]. The LES-CHT combination can then be enriched with a radiation solver to yield a comprehensive multiphysics approach to determine radiative, convective and conductive heat transfers at the wall as in Refs. [23,24]. Such multiphysics simulations of the 
aforementioned DLR test rig are the long-term objective of this study. In practice, the simulation of the full test rig with all components participating to the combustor heat transfer mechanisms is cumbersome. Indeed, with a pressure housing, the elements to consider would be :

$\circ$ the participating reactive flow inside the combustor,

o the heat conduction (and radiative transfer through the quartz windows 1) in the combustor walls,

o the cooling system inside the combustor walls and at the outer side of the quartz windows 1 ,

$\circ$ the flow and radiative transfer in the casing,

0 the heat conduction (and radiative transfer through the quartz windows 2) in the casing walls,

$\circ$ the external free convection and thermal radiation exchange between the casing outer walls and its surrounding experimental room.

Instead, only the first two items can be resolved in the coupled simulation, provided that adequate external boundary conditions are prescribed through models. An assessment of the modeling methodology of external heat transfer of the considered DLR test rig is therefore needed, which is the objective of the present study. Carrying out a sensitivity study of the model parameters with RANS simulations would be too costly or even unaffordable with LES. Assuming uniform window temperature on each faces enables instead a quick model assessment to select a final and simplified version of the external heat transfer boundary condition to be used later in CFD computations.

In particular, one must take care of the semi-transparent nature of the viewing windows. While absent in industrial systems, these windows, often present in laboratory-scale models, can strongly modify the internal and external radiative heat transfer. Surprisingly, this effect on the combustor heat transfer has not been thoroughly investigated. In fact, the validation of coupled CFD simulation with thermal radiation has mainly been involved with unconfined flames [25] mostly because of the usually unknown wall temperature in confined configurations. Applications to confined combustor with opaque boundaries as in [26] require providing the wall emissivity which can be quite uncertain depending on the type and state of the material. To the best of our knowledge, only a couple of studies from French research groups have investigated combustors enclosed with viewing windows $[21,22,24,27]$. The windows properties were either not detailed or a fixed averaged emissivity was specified [24,27]. Given the number of laboratory-scale combustor equipped with viewing windows, the number of such studies is expecting to grow significantly along with the need to assess the impact of semitransparent windows.

The study is organized as follows. The combustor configuration is first presented along with the notations of the different physical phenomena that are considered. The models for the different parts of the system and associated heat transfer

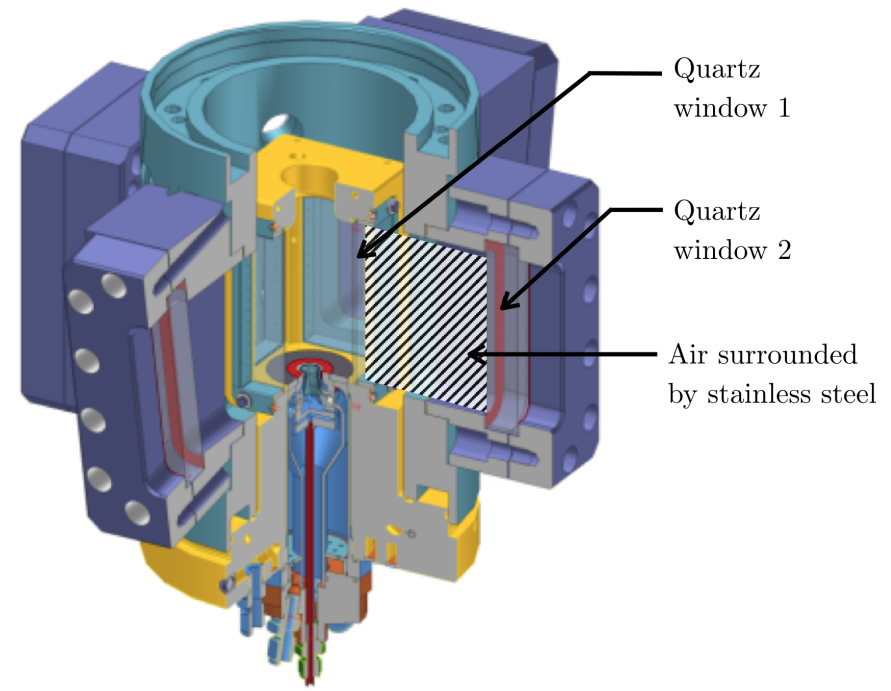

FIGURE 1. Design of burner, combustion chamber and optical module of pressure housing.

mechanisms are then detailed: convective heat transfer from the quartz windows 1 cooling system and free convection on the quartz windows 2 , the quartz windows radiative properties, the radiative transfer inside the pressure housing and the heat conduction through the quartz window. The derived model is validated against experimental measurements of the quartz windows 1 temperature on both inner and outer sides. A sensitivity analysis of the model finally allows for studying the impact of the different model components on the combustion chamber window temperatures in order to retain a simplified version which can be easily implemented as an external boundary condition.

\section{PRESENTATION OF THE COMBUSTION CHAMBER THERMAL ENVIRONMENT}

Figure 1 presents the design of the overall burner (combustion chamber and pressure housing) and the optical module composed of different quartz windows (for the combustion chamber and the pressure housing).

The burner injector consists of three concentric swirled nozzles. Air is injected through a central and an annular nozzle, while fuel is injected between these two nozzles. For some operating points, additional cold air is supplied $80 \mathrm{~mm}$ downstream of this primary injector through four secondary air ports in the combustion chamber posts. Details on the three considered configurations are given in Table 1.

The walls of the combustion chamber are composed of four quartz windows of thickness $e_{1}=3 \mathrm{~mm}$, and four copper posts at each corner cooled to about $333 \mathrm{~K}$. The bottom of the combus- 


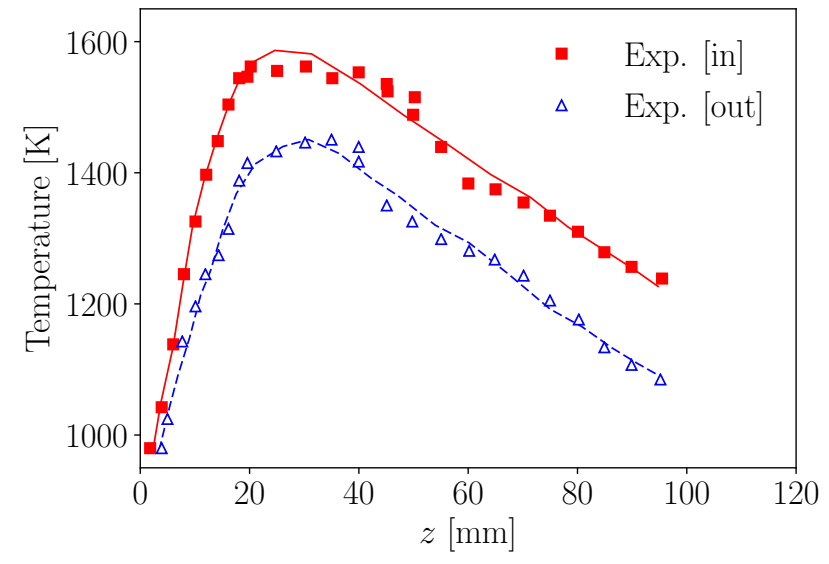

FIGURE 2. Measured temperatures of the inner and outer surface of the combustion chamber windows along the vertical axis for Case 1 [28]. Lines correspond to fits of the experimental data.

tion chamber is composed of a stainless steel plate whose temperature is estimated around $650 \mathrm{~K}$. For each operating point, the temperature at the inner and outer window surfaces has been measured using laser induced phosphorescence (LIP) along the window vertical centerline. The corresponding temperature profile for case 1 along the vertical axis of the quartz windows is given in Fig. 2. The measurement error was derived to be about $0.5 \%$ for low and intermediate temperature and about $3 \%$ for the peak temperatures [28].

The pressure housing is composed of stainless steel, whose mean temperature is noted $T_{3}=313 \mathrm{~K}$, and four quartz windows, parallel to the ones of the combustion chamber and with a thickness $e_{2}=40 \mathrm{~mm}$. The air in the pressure housing is injected as a film cooling on the quartz windows 1 and exhausts to the top.

The notations to describe heat transfer mechanisms through one window of the combustor are presented in Fig. 3. The model accounts for conduction in both quartz windows 1 and 2, radiation between the two sets of windows and the pressure housing in between and boundary layers at the interfaces between the both quartz windows and air. The model is assessed by considering uniform temperature fields in the vertical and spanwise directions. This allows for deriving a simple yet coarse model to discriminate between effects of different phenomena on the predicted window heat flux and temperature. The considered quantities are then the space-averaged window temperatures and fluxes. The temperature at the inner and outer surfaces of the combustion chamber quartz windows are denoted as $T_{\text {in }}$ and $T_{\text {out }}$, respectively. $T_{2 a}$ and $T_{2 b}$ denote the inner and outer temperatures of the pressure housing windows. While the window temperature profiles are in fact inhomogeneous (see Fig. 2), the space-averaged conductive flux computed from the inhomogeneous profiles on the inner and outer sides of the window is very similar to the one

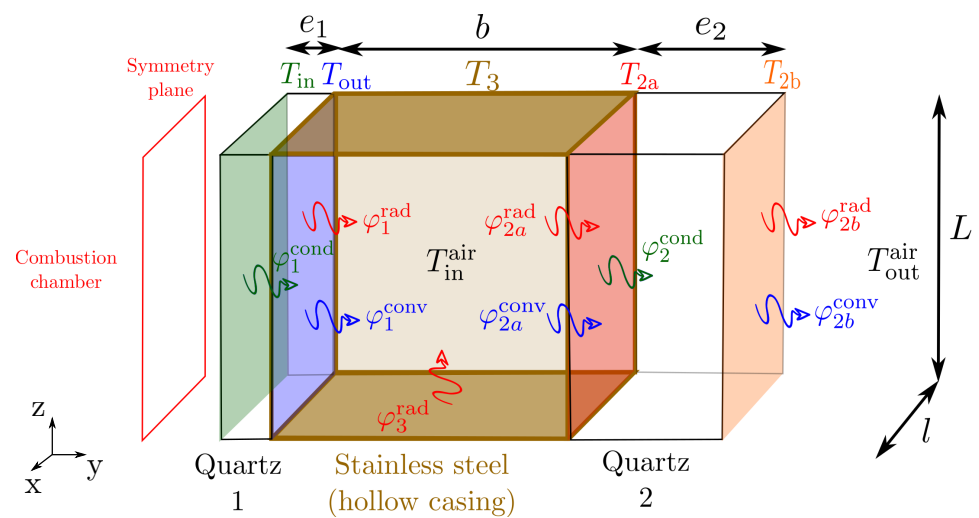

FIGURE 3. Representation of the heat exchanges outside the combustion chamber. The defined sizes are $L=120 \mathrm{~mm}, l=60 \mathrm{~mm}, b=108$ $\mathrm{mm}, e_{1}=3 \mathrm{~mm}$ and $e_{2}=40 \mathrm{~mm}$. Brown faces correspond to stainless steel surrounding air inside the pressure housing.

estimated from space-averaged temperatures. However, the $T^{4}$ non-linear dependency of wall radiative flux with temperature certainly strongly enhances the window profile inhomogeneity and is expected to limit the accuracy of the simplified model.

The energy balance at each interface is given by

$$
\left\{\begin{array}{l}
\varphi_{1}^{\mathrm{cond}}=\varphi_{1}^{\mathrm{rad}}+\varphi_{1}^{\mathrm{conv}} \\
\varphi_{2 \mathrm{a}}^{\mathrm{rad}}+\varphi_{2 \mathrm{a}}^{\mathrm{conv}}=\varphi_{2}^{\mathrm{cond}} \\
\varphi_{2}^{\mathrm{cond}}=\varphi_{2 \mathrm{~b}}^{\mathrm{rad}}+\varphi_{2 \mathrm{~b}}^{\mathrm{conv}} \\
\text { Eqs. (17) and (18) linking } \varphi_{2 \mathrm{a}}^{\mathrm{rad}} \text { and } \varphi_{1}^{\mathrm{rad}}
\end{array}\right.
$$

Then, fixing the inner surface temperature $T_{\text {in }}$ of the first quartz window, all the other fluxes and temperatures of the system can be determined. The fixed homogeneous temperature $T_{\text {in }}$ is set according to the experimental temperature data averaged along the centreline.

In the following the thermodynamical properties of air $\left(k^{\mathrm{air}}(T), \mu^{\mathrm{air}}(T), c_{p}^{\mathrm{air}}(T)\right)$ are computed from polynomial fits [29]. The air temperatures are taken equal to $T_{\mathrm{in}}^{\mathrm{air}}=333 \mathrm{~K}$ inside the pressure housing and $T_{\mathrm{out}}^{\mathrm{air}}=300 \mathrm{~K}$ outside the pressure housing (ambient air). The air density $\rho^{\text {air }}(T, p)$ is computed through the ideal gas law. The pressure inside the housing is 3 bar.

\section{CONVECTIVE TRANSFER MODELING Quartz windows 1 cooling system}

The cooling system of the combustion chamber windows is illustrated in Fig. 4. Each left and right side of the quartz windows 1 is cooled on the outer face through $N_{\text {jet }}=14$ small orifices with a total flow rate of $150 \mathrm{slm}$, which corresponds to an 
TABLE 1. Considered operating points: Pressure, $p$, volume flow rates for air through burner (central and ring), $Q_{\text {air,c }}$ and $Q_{\text {air,r }}$, fuel, $Q_{\text {fuel }}$, oxidation air through secondary air inlet, $Q_{\text {oxi }}$, primary and global equivalence ratios, $\Phi$ and $\Phi_{\text {global }}$, primary and global thermal powers, $P$ and $P_{\text {global }}$, and

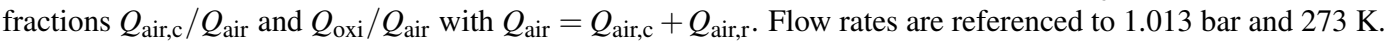

\begin{tabular}{|c|c|c|c|c|c|c|c|c|c|c|c|}
\hline & $\begin{array}{c}p \\
{[\text { bar] }}\end{array}$ & $\begin{array}{c}\Phi \\
{[-]}\end{array}$ & $\begin{array}{c}P_{\text {primary }} \\
{[\mathrm{kW}]}\end{array}$ & $\begin{array}{l}Q_{\text {air,c }} \\
{[\mathrm{slm}]}\end{array}$ & $\begin{array}{c}Q_{\text {air,r }} \\
{[\mathrm{slm}]}\end{array}$ & $\begin{array}{c}Q_{\text {fuel }} \\
\text { [slm] }\end{array}$ & $\begin{array}{c}Q_{\text {oxi }} \\
\text { [slm] }\end{array}$ & $\begin{array}{c}\frac{Q_{\text {air,c }}}{Q_{\text {air }}} \\
{[-]}\end{array}$ & $\begin{array}{c}\frac{Q_{\text {oxi }}}{Q_{\text {air }}} \\
{[-]}\end{array}$ & $\begin{array}{c}\Phi_{\text {global }} \\
{[-]}\end{array}$ & $\begin{array}{r}P_{\text {global }} \\
{[\mathrm{kW}]}\end{array}$ \\
\hline Case 1 & 3 & 0.9 & 32.2 & 156.0 & 365.1 & 32.7 & 208.2 & 0.3 & 0.4 & 0.64 & 32.2 \\
\hline Case 2 & 3 & 1.2 & 32.2 & 140.8 & 328.5 & 39.3 & 0 & 0.3 & 0 & 1.2 & 32.2 \\
\hline Case 3 & 3 & 1.2 & 32.2 & 140.8 & 328.5 & 39.3 & 187.4 & 0.3 & 0.4 & 0.86 & 38.6 \\
\hline
\end{tabular}

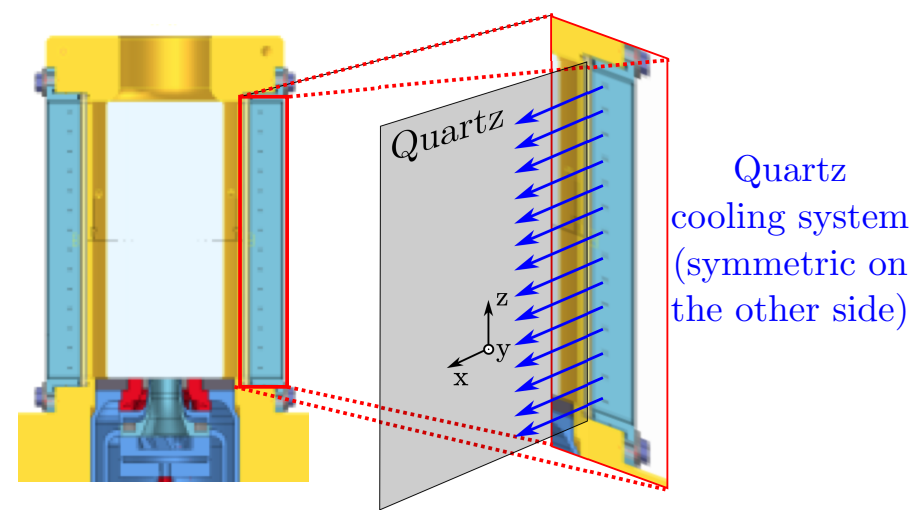

FIGURE 4. Combustion chamber quartz cooling system (from ISF communication [30] )

exit velocity $u_{\text {jet }}$ of approximatively $15 \mathrm{~m} / \mathrm{s}$. The generated cooling flow is modeled as a bidimensional wall jet whose equivalent thickness $e_{\mathrm{eq}}$ and exit velocity $u_{\mathrm{wjet}}$ are defined to conserve the total mass and momentum fluxes. These two conditions result in $u_{\text {wjet }}=u_{\text {jet }}$ and $e_{\text {eq }}=\left(N_{\text {jet }} \pi d_{\text {jet }}^{2}\right) /(4 L)$, where $d_{\text {jet }}$ and $L$ are the diameter of each cooling jet and the window height, respectively.

The Reynolds number based on the equivalent wall jet thickness $e_{\mathrm{eq}}$ is $\operatorname{Re}_{e_{\mathrm{eq}}}=169$, which indicates that the flow is laminar. Selfsimilar solutions of such incompressible wall jets have been studied in fluid mechanics [31] and heat transfer [32]. Schwarz and Caswell [32] have derived a formulation of the heat transfer coefficient for the isothermal wall case whose validity has been investigated numerically [33]. Later, Issa [34] has proposed a general relationship of the evolution of Nusselt number as a function of the distance from the leading edge, the local Prandtl number and the bulk Reynolds number in the case of isothermal and constant heat flux, which is retained here:

$$
\mathrm{Nu}_{1}(x, z)=\frac{h_{1}(x, z)\left(x+l_{\mathrm{th}}\right)}{k^{\mathrm{air}}}=0.345 \operatorname{Pr}^{0.34} \operatorname{Re}_{e_{\mathrm{eq}}}^{0.75}\left(\frac{x+l_{\mathrm{th}}}{e_{\mathrm{eq}}}\right)^{1 / 4}
$$

with $h_{1}(x, z)$ the local convective heat transfer coefficient on the outer surface of the quartz windows 1 . This equation is considered for each half window separated by the vertical centerline given that cooling air is injected at each lateral side. All physical properties in the fluid are computed at the film temperature approximated as $T_{\text {film }}(x, z)=\left(T_{\text {out }}(x, z)+T_{\text {in }}^{\text {air }}\right) / 2$. The thermal length $l_{\mathrm{th}}$, setting the fictive origin of the formula, is given by $l_{\text {th }} / e_{\text {eq }}=0.047 \cdot \operatorname{Re}_{e_{\text {eq }}}-0.28$.

In a 3-D simulation, the non-homogeneous profile of the heat transfer coefficient $h_{1}(x, z)$ is used directly. In the considered study based on surface averaged temperature, a global heat transfer coefficient $\overline{h_{1}}$ should be considered instead to compute the heat flux at the outer surface of the quartz windows 1 as:

$$
\varphi_{1}^{\mathrm{conv}}=\overline{h_{1}}\left(T_{\mathrm{out}}-T_{\mathrm{in}}^{\mathrm{air}}\right)
$$

Combining the evaluation $\overline{h_{1}}$ from the average of $h_{1}(x)$ with the average temperature provided by the experimental data on the centerline $(x=l / 2)$ yield incorrect results. This is attributed to the variations of the experimental field of temperature in the transverse directions. This is corrected by considering $\overline{h_{1}}=$ $h_{1}(x=l / 2)$ instead.

\section{Free convection on the quartz windows 2}

The convective heat transfer coefficient $h_{2 \mathrm{a}}^{\text {conv }}$ at the inner side of the quartz windows 2 is determined by a free convection boundary layer. The corresponding Nusselt number $\mathrm{Nu}_{2 \mathrm{a}}^{\mathrm{L}}=$ $\frac{h_{2 \mathrm{a}}^{\text {conv }} L}{k^{\text {air }}}$ is calculated through the following correlation [35] for a 
vertical plate:

$$
\mathrm{Nu}_{2 \mathrm{a}}^{\mathrm{L}}=\left[0.825+\frac{0.387 \mathrm{Ra}^{\mathrm{L}^{1 / 6}}}{\left[1+0.628 \mathrm{Pr}^{-9 / 16}\right]^{8 / 27}}\right]^{2},
$$

where the Rayleigh number $\mathrm{Ra}^{\mathrm{L}}$ is

$$
\mathrm{Ra}^{\mathrm{L}}=\mathrm{Gr}^{\mathrm{L}} \mathrm{Pr}, \quad \text { with } \quad \mathrm{Gr}^{\mathrm{L}}=\frac{g \beta\left(T_{3}-T_{\text {in }}^{\text {air }}\right) L^{3}}{\left(v^{\text {air }}\right)^{2}}
$$

the Grashof number, the gravity acceleration $g$, the air thermal expansion coefficient $\beta(T)=1 / T$ and the air kinematic viscosity $v^{\text {air }}=\mu^{\text {air }} / \rho^{\text {air }}$. All properties are evaluated at the film temperature $T_{2 \mathrm{a}}^{f}=\left(T_{\mathrm{in}}^{\text {air }}+T_{2 \mathrm{a}}\right) / 2$. The heat transfer coefficient $h_{2 \mathrm{~b}}^{\text {conv }}$ on the outer side of the quartz windows 2 is determined similarly, while using the film temperature: $T_{2 \mathrm{~b}}^{f}=\left(T_{\mathrm{out}}^{\mathrm{air}}+T_{2 \mathrm{~b}}\right) / 2$. Finally, the convective heat fluxes at the inner and outer surfaces of the second quartz windows are written as

$$
\begin{aligned}
& \varphi_{2 a}^{\text {conv }}=h_{2 \mathrm{a}}^{\text {conv }}\left(T_{\text {in }}^{\text {air }}-T_{2 \mathrm{a}}\right) \\
& \varphi_{2 b}^{\text {conv }}=h_{2 \mathrm{~b}}^{\text {conv }}\left(T_{2 \mathrm{~b}}-T_{\text {out }}^{\text {air }}\right)
\end{aligned}
$$

\section{RADIATIVE EXCHANGES MODELING Quartz radiative properties}

The internal transmittance $\tau_{\lambda}$ provided by the manufacturer [36] for a $1-\mathrm{cm}$ quartz slab as a function of the wavelength $\lambda$ is presented in Fig. 5. It can be expressed as

$$
\tau_{\lambda}=\exp \left(-4 \pi k_{2, \lambda} e / \lambda\right)=\exp \left(-\kappa_{2, \lambda} e\right)
$$

where $e$ is the slab thickness, $n_{2, \lambda}$ is the refractive index (real part of the complex index of refraction), and $k_{2, \lambda}$ is the absorptive index (imaginary part of the complex index of refraction). The absorption coefficient $\kappa_{2, \lambda}=4 \pi k_{2, \lambda} / \lambda$ is usually considered instead of $k_{2, \lambda}$ in thermal radiation. The wavelength dependency of the quartz absorption coefficient $\kappa_{2, \lambda}$ is determined from the internal transmittance profile in Fig. 5, allowing then to compute $\tau_{\lambda}$ for any quartz thickness $e$.

Considering an interface with air (refractive index equal to 1 ), the normal reflectance $\rho_{\lambda}$ is given by

$$
\rho_{\lambda}=\frac{\left(1-n_{2, \lambda}\right)^{2}+k_{2, \lambda}^{2}}{\left(1+n_{2, \lambda}\right)^{2}+k_{2, \lambda}^{2}}
$$

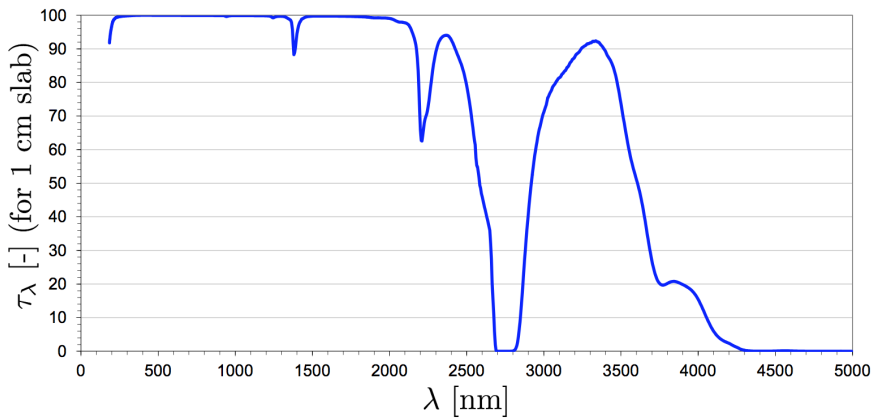

FIGURE 5. Internal transmittance of a $1 \mathrm{~cm}$ Corning HPFS 7980 quartz slab (from [36]).

where the evolution of $n_{2, \lambda}$ with wavelength is also been provided by the manufacturer [36]. The absorptance $\alpha_{\lambda}$ and emittance $\varepsilon_{\lambda}$ are given by $\varepsilon_{\lambda}=\alpha_{\lambda}=1-\tau_{\lambda}-\rho_{\lambda}$.

The quartz windows properties are expressed in terms of a slab absorptance $\left(A_{\lambda}^{\text {slab }}\right)$, a slab transmittance $\left(T_{\lambda}^{\text {slab }}\right)$ and a slab reflectance $\left(R_{\lambda}^{\text {slab }}\right)$ which account for multiple normal reflections inside the quartz slab and are defined as [37]:

$$
\begin{aligned}
A_{\lambda}^{\text {slab }} & =\frac{\left(1-\rho_{\lambda}\right)\left(1-\tau_{\lambda}\right)}{1-\rho_{\lambda} \tau_{\lambda}} \\
T_{\lambda}^{\text {slab }} & =\frac{\left(1-\rho_{\lambda}\right)^{2} \tau_{\lambda}}{1-\rho_{\lambda}^{2} \tau_{\lambda}^{2}} \\
R_{\lambda}^{\text {slab }} & =\rho_{\lambda}\left[1+\frac{\left(1-\rho_{\lambda}\right)^{2} \tau_{\lambda}^{2}}{1-\rho_{\lambda}^{2} \tau_{\lambda}^{2}}\right]
\end{aligned}
$$

Figure 6 presents the computed evolution of these three quantities with wavelength $\lambda$ for a quartz slab of thickness $e=$ $e_{1}=3 \mathrm{~mm}$ which corresponds to the quartz windows 1 . These detailed properties of absorptance, transmittance and reflectance are simplified in a spectral band model where only opaque (transmittance equal to zero) and transparent spectral bands are considered. To do so, a threshold value $T_{\text {threshold }}^{\text {slab }}$ is defined. For each wavelength $\lambda$, if $T_{\lambda}^{\text {slab }}>T_{\text {threshold }}^{\text {slab }}$, the quartz is considered as transparent, unless the quartz is considered as opaque. For the opaque bands, the absorptance and emittance are identical. Computations of radiative transfer consider hemispherical properties instead of the normal absorptance or emittance to account for the effects of directional dependency of this coefficients. The hemispherical absorptance $A_{\lambda}^{\text {slab,hem }}$ (or $\varepsilon_{\lambda}^{\text {slab,hem }}=A_{\lambda}^{\text {slab,hem }}$ ) is computed explicitly as a function of $n_{2, \lambda}$ and $k_{2, \lambda}$ through a rather long formula given in Eq. (3.20) in Ref. [38]. For the considered quartz material, noting that $k_{2, \lambda} \ll n_{2, \lambda}$ can simplify the calculation. The properties in the transparent and opaque spectral bands are defined as: 


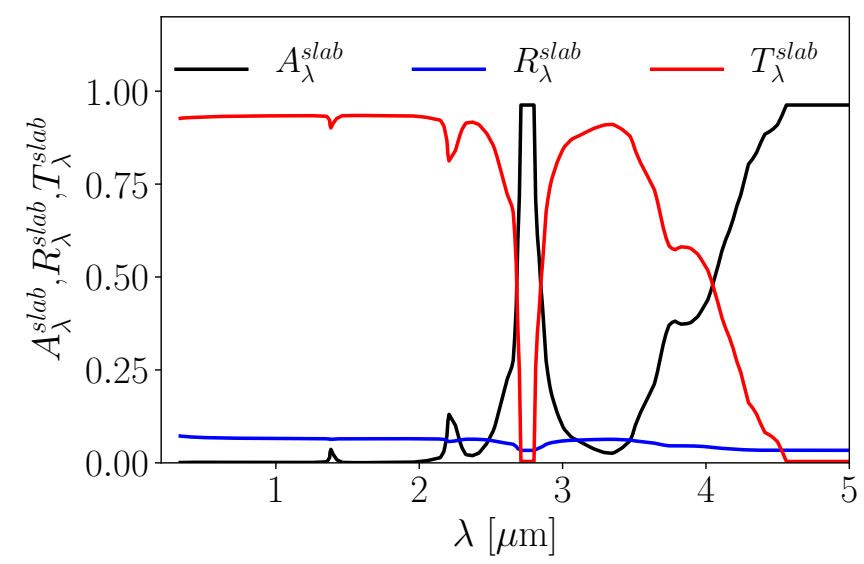

FIGURE 6. Computed quartz slab absorptance $\left(A_{\lambda}^{\text {slab }}\right)$, transmittance $\left(T_{\lambda}^{\text {slab }}\right)$ and reflectance $\left(R_{\lambda}^{\text {slab }}\right)$ as a function of the wavelength $\lambda$ for a 3-mm thickness. The quartz reference is Corning HPFS 7980.

- For a transparent spectral band (i.e. when $T_{\lambda}^{\text {slab }}>T_{\text {threshold }}^{\text {slab }}$ ):

$$
\begin{aligned}
T_{\lambda}^{\text {slab,model }} & =\frac{\left(1-\rho_{\lambda}\right)^{2}}{1-\rho_{\lambda}^{2}} \\
A_{\lambda}^{\text {slab,model }} & =0 \\
R_{\lambda}^{\text {slab,model }} & =1-T_{\lambda}^{\text {slab,model }},
\end{aligned}
$$

- For an opaque spectral band (i.e. $T_{\lambda}^{\text {slab }}<T_{\text {threshold }}^{\text {slab }}$ ):

$$
\begin{aligned}
& T_{\lambda}^{\text {slab,model }}=0 \\
& A_{\lambda}^{\text {slab,model }}=A_{\lambda}^{\text {slab,hem }} \\
& R_{\lambda}^{\text {slab,model }}=1-A_{\lambda}^{\text {slab,hem }} .
\end{aligned}
$$

Global properties of the quartz slab can also be obtained by integrating the radiative properties on the spectrum. The total absorptance $\overline{A^{\text {slab }}}$, reflectance $\overline{R^{\text {slab }}}$ and transmittance $\overline{T^{\text {slab }}}$ are expressed as:

$$
\begin{aligned}
& \overline{A^{\mathrm{slab}}}(T)=\int_{\lambda=0}^{+\infty} A_{\lambda}^{\mathrm{slab}} I_{\lambda}^{\circ}(T) d \lambda / \int_{\lambda=0}^{+\infty} I_{\lambda}^{\circ}(T) d \lambda \\
& \overline{R^{\mathrm{slab}}}(T)=\int_{\lambda=0}^{+\infty} R_{\lambda}^{\mathrm{slab}} I_{\lambda}^{\circ}(T) d \lambda / \int_{\lambda=0}^{+\infty} I_{\lambda}^{\circ}(T) d \lambda \\
& \overline{T^{\mathrm{slab}}}(T)=\int_{\lambda=0}^{+\infty} T_{\lambda}^{\mathrm{slab}} I_{\lambda}^{\circ}(T) d \lambda / \int_{\lambda=0}^{+\infty} I_{\lambda}^{\circ}(T) d \lambda
\end{aligned}
$$

To determine the threshold value of the spectral band model, a criterion is needed. It has been chosen to match the total transmittance evolution with temperature when compared to the one obtained with the detailed slab transmittance $T_{\lambda}^{\text {slab }}$. This threshold value is dependent on the thickness of the quartz slab. The obtained values are $T_{\text {threshold }}^{\text {slab }}=0.57$ for a 3-mm-thick quartz slab and $T_{\text {threshold }}^{\text {slab }}=0.51$ for a $40-\mathrm{mm}$-thick quartz slab. This yields an average error on the temperature range of interest of $0.66 \%$ and $0.68 \%$, respectively. The corresponding obtained spectral band model for the 3-mm quartz slab is presented in Fig 7.

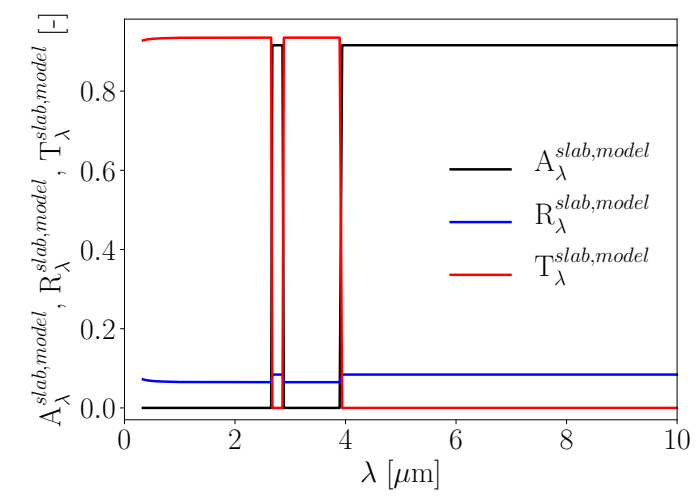

FIGURE 7. Transparent and non-transparent spectral band model for a $3 \mathrm{~mm}$ thickness Corning HPFS 7980 quartz.

The corresponding evolution of the Planck mean quantities with temperature is plotted in Fig. 8. It can be observed that for rays coming from a source at low temperature, the quartz is mostly absorbing, whereas it is transparent at high temperatures.

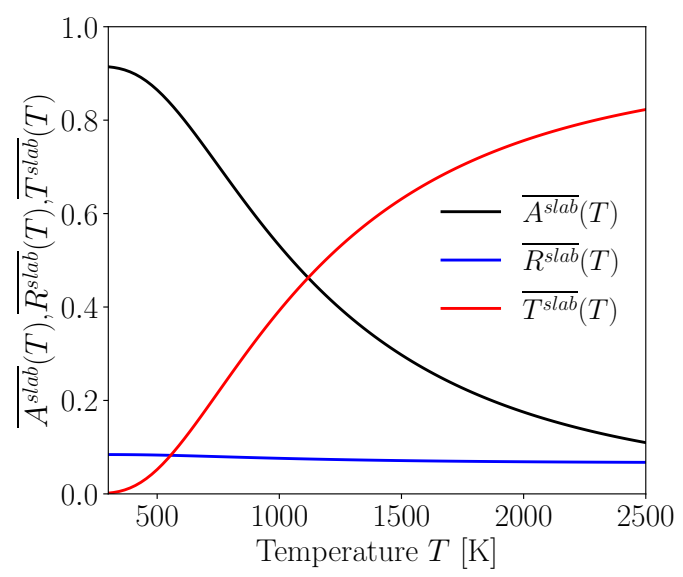

FIGURE 8. Planck mean modeled external absorptance $\left(\overline{A^{\text {slab }}}(T)\right)$, transmittance $\left(\overline{T^{\text {slab }}}(T)\right)$ and reflectance $\left(\overline{R^{\text {slab }}}(T)\right)$ as a function of incident source temperature $T$ for a $3 \mathrm{~mm}$ thickness Corning HPFS 7980 quartz. 
We finally define two spectral emittances and reflectances for the quartz windows $1\left(A_{\lambda, 1}^{\text {slab }}\right.$ and $\left.R_{\lambda, 1}^{\text {slab }}\right)$ and the quartz windows $2\left(A_{\lambda, 2}^{\text {slab }}\right.$ and $\left.R_{\lambda, 2}^{\text {slab }}\right)$ :

$$
\begin{array}{ll}
A_{\lambda, 1}^{\text {slab }}=A_{\lambda}^{\text {slab,model }}, R_{\lambda, 1}^{\text {slab }}=R_{\lambda}^{\text {slab,model }} & \text { with } T_{\text {threshold }}^{\text {slab }}=0.57 \\
A_{\lambda, 2}^{\text {slab }}=A_{\lambda}^{\text {slab,model }}, R_{\lambda, 2}^{\text {slab }}=R_{\lambda}^{\text {slab,model }} & \text { with } T_{\text {threshold }}^{\text {slab }}=0.51
\end{array}
$$

\section{Radiative transfer inside the pressure housing}

This section deals with the radiative transfer modeling to estimate the radiative fluxes $\varphi_{1}^{\mathrm{rad}}$ and $\varphi_{2 \mathrm{a}}^{\mathrm{rad}}$ at the windows 1 and 2, respectively. The radiative flux at the steel casing is denoted by $\varphi_{3}^{\mathrm{rad}}$. The pressure housing around each pair of quartz windows 1 and 2 is modeled as a closed box domain (see Fig. 3) delimited by the combustion chamber window of surface area $S_{1}=L \cdot l$, the pressure housing window of surface area $S_{2}=S_{1}$, and the surrounding steel casing of surface area $S_{3}=2 \cdot(L+l) \cdot b$. View factors $F_{i j}$ between surfaces $S_{i}$ and $S_{j}$ are

$$
\begin{array}{ll}
F_{11}=0 & F_{12}=\mathscr{F}(L, l, b) \\
F_{21}=\mathscr{F}(L, l, b) & F_{22}=0 \\
F_{31}=F_{13} S_{1} / S_{3} & F_{32}=F_{23} S_{2} / S_{3} \\
F_{13}=1-F_{11}-F_{12}=1-F_{12} & F_{33}=1-F_{31}-F_{32} \\
F_{23}=1-F_{21}-F_{22}=1-F_{21} &
\end{array}
$$

where $\mathscr{F}(L, l, b)$ is given by the expression [38]:

$$
\begin{aligned}
\mathscr{F}(L, l, b) & =\frac{1}{\pi \mathscr{U} \mathscr{V}}\left[\ln \left(\frac{\mathscr{U}_{1}^{2} \mathscr{V}_{1}^{2}}{\mathscr{U}_{1}^{2}+\mathscr{V}_{1}^{2}-1}\right)+2 \mathscr{U}\left(\mathscr{V}_{1} \arctan \left(\frac{\mathscr{U}}{\mathscr{V}_{1}}\right)\right.\right. \\
& \left.-\arctan \mathscr{U})+2 \mathscr{V}\left(\mathscr{U}_{1} \arctan \left(\frac{\mathscr{V}}{\mathscr{U}_{1}}\right)-\arctan (\mathscr{V})\right)\right]
\end{aligned}
$$

with $\mathscr{U}=L / b, \mathscr{V}=l / b, \mathscr{U}_{1}=\sqrt{1+\mathscr{U}^{2}}$ and $\mathscr{V}_{1}=\sqrt{1+\mathscr{V}^{2}}$.

Then, equivalent isotropic radiative intensity are introduced: $I_{\lambda, 1}^{l}, I_{\lambda, 1}^{i}, I_{\lambda, 2 \mathrm{a}}^{l}, I_{\lambda, 2 \mathrm{a}}^{i}, I_{\lambda, 3}^{l}, I_{\lambda, 3}^{i}$ are, respectively, the leaving and incident intensities at quartz windows 1 , quartz windows $2 \mathrm{a}$ and casing surfaces. They are used to express the radiative fluxes on surfaces $S_{1}, S_{2}$ and $S_{3}$ as

$$
\begin{aligned}
& \varphi_{1}^{\mathrm{rad}}=\pi \int_{\lambda=0}^{+\infty}\left(I_{\lambda, 1}^{l}-I_{\lambda, 1}^{i}\right) d \lambda \\
& \varphi_{2 \mathrm{a}}^{\mathrm{rad}}=-\pi \int_{\lambda=0}^{+\infty}\left(I_{\lambda, 2 \mathrm{a}}^{l}-I_{\lambda, 2 \mathrm{a}}^{i}\right) d \lambda \\
& \varphi_{3}^{\mathrm{rad}}=\pi \int_{\lambda=0}^{+\infty}\left(I_{\lambda, 3}^{l}-I_{\lambda, 3}^{i}\right) d \lambda
\end{aligned}
$$

The introduced intensities are obtained by solving spectrally the following system of equations:

$$
\begin{aligned}
& \left\{\begin{array}{l}
I_{\lambda, 1}^{l}=A_{\lambda, 1}^{\mathrm{slab}} I_{\lambda}^{\circ}\left(T_{\mathrm{out}}\right)+R_{\lambda, 1}^{\mathrm{slab}} I_{\lambda, 1}^{i} \\
I_{\lambda, 1}^{i}=F_{11} I_{\lambda, 1}^{l}+F_{21} I_{\lambda, 2 \mathrm{a}}^{l}+F_{31} I_{\lambda, 3}^{l}
\end{array}\right. \\
& \left\{\begin{array}{l}
I_{\lambda, 2 \mathrm{a}}^{l}=A_{\lambda, 2}^{\mathrm{slab}} I_{\lambda}^{\circ}\left(T_{2 \mathrm{a}}\right)+R_{\lambda, 2}^{\text {slab }} I_{\lambda, 2 \mathrm{a}}^{i} \\
I_{\lambda, 2 \mathrm{a}}^{i}=F_{12} I_{\lambda, 1}^{l}+F_{22} I_{\lambda, 2 \mathrm{a}}^{l}+F_{32} I_{\lambda, 3}^{l}
\end{array}\right. \\
& \left\{\begin{array}{l}
I_{\lambda, 3}^{l}=\varepsilon_{\lambda, 3} I_{\lambda}^{\circ}\left(T_{3}\right)+\left(1-\varepsilon_{\lambda, 3}\right) I_{\lambda, 3}^{i} \\
I_{\lambda, 3}^{i}=F_{13} I_{\lambda, 1}^{l}+F_{23} I_{\lambda, 2 \mathrm{a}}^{l}+F_{33} I_{\lambda, 3}^{l}
\end{array}\right.
\end{aligned}
$$

with the temperature of the stainless steel $T_{3}=313 \mathrm{~K}$.

The emissivity of unoxidized stainless steel typically ranges between 0.2 and $0.3[37,38]$. The value $\varepsilon_{\lambda, 3}=0.25$ is retained.

\section{External radiative transfer}

The radiative flux $\varphi_{2 b}^{\text {rad }}$ at the outer side of the pressure housing quartz windows (quartz windows 2 ) is written as

$$
\varphi_{2 \mathrm{~b}}^{\mathrm{rad}}=\int_{\lambda=0}^{+\infty} A_{\lambda, 2}^{\mathrm{slab}}\left(I_{\lambda}^{\circ}(T)-I_{\lambda}^{\circ}\left(T_{\mathrm{out}}^{\mathrm{air}}\right)\right) d \lambda
$$

\section{CONDUCTIVE TRANSFER MODELING Quartz thermal conductivity}

Quartz thermal conductivity varies strongly with temperature. Such data is generally not provided by the quartz manufacturers. In a recent study [39], this dependency with temperature has been characterized based on data from the manufacturer Heraeus [5]. The data are reported in Fig. 9 along with a polynomial fit of this data:

$$
\frac{k^{\mathrm{slab}}(T)}{k^{0}}=a_{0}+a_{1}\left(\frac{T}{T_{0}}\right)+a_{2}\left(\frac{T}{T_{0}}\right)^{2}+a_{3}\left(\frac{T}{T_{0}}\right)^{3}
$$

with: $a_{0}=0.97980, a_{1}=-0.10063, a_{2}=0.13677, a_{3}=$ $-0.011744, T_{0}=293 \mathrm{~K}$ and $k^{0}=k^{\mathrm{slab}}(293 \mathrm{~K})=1.38 \mathrm{~W} / \mathrm{m} / \mathrm{K}$. The annealing temperature of these quartz windows is $1315 \mathrm{~K}$ [5]. A high uncertainty of the thermal conductivity is then expected for temperatures higher than $1315 \mathrm{~K}$ (shaded regions in Fig. 9).

\section{Heat conduction within quartz windows}

The modeling of the quartz windows radiative properties consider either opaque or transparent bands. One assumes therefore that there is no radiative transfer within the quartz material 


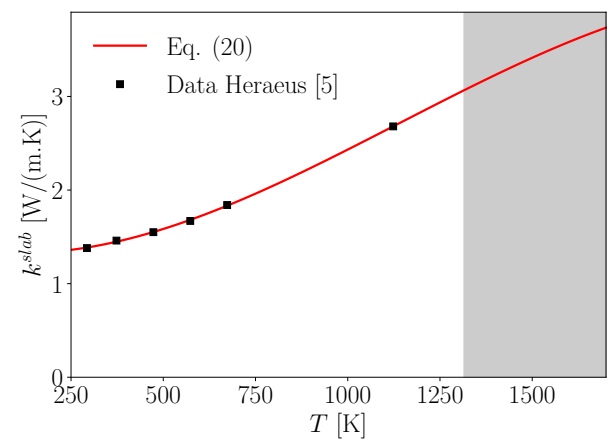

FIGURE 9. Thermal conductivity of quartz as a function of temperature $T$. Shaded region corresponds to quartz temperatures higher than their annealing temperature $(1315 \mathrm{~K})$.

and that the conductive heat flux within the window is unidirectional and constant given the assumption that the fields are uniform in vertical and spanwise directions. With the temperaturevarying thermal conductivity, the conductive flux through the quartz windows 1 is then estimated as

$$
\varphi_{1}^{\text {cond }}=-\frac{1}{e_{1}} \int_{T_{\text {in }}}^{T_{\text {out }}} k^{\text {slab }}(T) d T
$$

Similarly, the conductive flux $\varphi_{2}^{\text {cond }}$ through the external pressure housing quartz windows is

$$
\varphi_{2}^{\mathrm{cond}}=-\frac{1}{e_{2}} \int_{T_{2 \mathrm{a}}}^{T_{2 \mathrm{~b}}} k^{\mathrm{slab}}(T) d T
$$

\section{RESULTS OF THE DERIVED MODEL}

The different modeled system components and physical phenomena are coupled together through Eq. (1) which is solved with a root-finding algorithm (for example fsolve function from python or Matlab) by providing the inner surface temperature $T_{\text {in }}$ of the first quartz windows as the experimental one averaged along the vertical centerline. All the other fluxes and temperatures of the system are then determined. Table 2 presents the results for the three cases defined in Tab. 1. The reported spaceaveraged temperature $T_{\text {in }}^{\text {exp }}$ is computed by extrapolating the data from Fig. 2 up to the total height of the quartz windows of 120 $\mathrm{mm}$. Cases 1 and 2, being characterized by almost identical averaged temperature $T_{\mathrm{in}}$, yield identical results. Case 3 exhibits a smaller temperature at the combustor walls. For each case, the spatially-averaged experimental temperature of the outer surface of the combustor walls, $T_{\text {out }}^{\text {exp }}$, is correctly predicted with an error below $30 \mathrm{~K}$ compared. The extracted flux through the combustor

\begin{tabular}{ccccc}
\hline Quantity & Unity & Case 1 & Case 2 & Case 3 \\
\hline$T_{\text {in }}^{\text {exp }}$ & $\mathrm{K}$ & 1346 & 1345 & 1272 \\
\hline$\varphi_{1}^{\text {cond,exp }}$ & $\mathrm{kW} / \mathrm{m}^{2}$ & 131.2 & 125.8 & 110.0 \\
$\varphi_{1}^{\text {cond }}$ & $\mathrm{kW} / \mathrm{m}^{2}$ & 150.3 & 150.2 & 133.6 \\
$T_{\text {out }}^{\exp }$ & $\mathrm{K}$ & 1215 & 1219 & 1157 \\
$T_{\text {out }}$ & $\mathrm{K}$ & 1195 & 1194 & 1131 \\
\hline
\end{tabular}

TABLE 2. Thermal energy balance of the combustion chamber thermal environment.

walls, taken as identical to $\varphi_{1}^{\text {cond }}$, is within $20 \%$ approximatively of the correct value which has been estimated from the difference of the measured temperatures. It is important to notice that the uncertainty of this estimated conductive heat flux from measurements is about $27 \%$ considering an uncertainty of $\pm 20 \%$ on the quartz thermal conductivity, $\pm 0.1 \mathrm{~mm}$ on the quartz slab width and $\pm 3 \%$ on the measured quartz temperature. The fair agreement of the derived model is satisfactory given the macroscopic approach retained to model the different phenomena. In particular, it is worth recalling the certain limitation of the uniform temperature assumption on the quartz windows 1 surfaces. The inhomogeneous temperature profile can explain such a result. Indeed, the external face of the quartz windows 1 is actually cooled to $333 \mathrm{~K}$ in the vicinity of water-cooled metallic posts. A strong variation of the temperature field is then expected in the spanwise direction. Given the dependency of the radiative flux on temperature $\left(\propto T^{4}\right)$, radiative fluxes are certainly overestimated by considering the homogeneous $T_{\text {in }}$ as the average centerline temperature. Such an effect can explain the global overestimation of the extracted flux through the combustor walls. This error will be corrected in the future planned 3D simulations of conjugate heat transfer.

Details on the different fluxes for the case 1 are given in Tab. 3. For the quartz windows 1 , it can be observed that the radiative flux accounts for $30 \%$ of the total heat flux through the first quartz window, whereas $70 \%$ of the total heat flux corresponds to the cooling by the transverse jets. Both contributions sum up to the total extracted heat flux which is identical to the conductive flux between the inner and outer surfaces of the combustion chamber quartz window. This total flux is overestimated by about $15 \%$ in case 1 .

Only $12 \%$ of the radiative flux from quartz windows 1 is exchanged with quartz windows 2 , leading to a spatially-averaged radiative flux equal to $5.63 \mathrm{~kW} / \mathrm{m}^{2}$. The other part is directly exchanged with the pressure housing's stainless steel walls. With an opposite sign to this radiative flux, the quartz windows 2 exchanges $3.17 \mathrm{~kW} / \mathrm{m}^{2}$ with the ambient pressurized air through natural convection, resulting to a conductive heat flux in the 


\begin{tabular}{|c|c|c|c|c|c|}
\hline Quantity & Unity & $\begin{array}{c}\text { Case } \\
1\end{array}$ & $\begin{array}{c}\text { Case } \\
1 \mathrm{~b}\end{array}$ & $\begin{array}{c}\text { Case } \\
1 \mathrm{c}\end{array}$ & $\begin{array}{c}\text { Case } \\
1 \mathrm{~d}\end{array}$ \\
\hline \multicolumn{6}{|c|}{ quartz windows 1 [outer] } \\
\hline$\varphi_{1}^{\text {cond,exp }}$ & $\mathbf{k W} / \mathbf{m}^{2}$ & 131.2 & 60.5 & 131.2 & 131.2 \\
\hline$\varphi_{1}^{\text {cond }}$ & $\mathbf{k W} / \mathbf{m}^{2}$ & 150.4 & 121.4 & 150.8 & 152.3 \\
\hline$\varphi_{1}^{\text {conv }}$ & $\mathrm{kW} / \mathrm{m}^{2}$ & 104.6 & 86.2 & 104.5 & 104.2 \\
\hline$\varphi_{1}^{\mathrm{rad}}$ & $\mathrm{kW} / \mathrm{m}^{2}$ & 45.8 & 35.2 & 46.3 & 48.1 \\
\hline$T_{\text {in }}^{\exp }$ & $\mathrm{K}$ & 1346 & 1346 & 1346 & 1346 \\
\hline $\mathbf{T}_{\text {out }}^{\exp }$ & $\mathbf{K}$ & 1215 & 1215 & 1215 & 1215 \\
\hline $\mathbf{T}_{\text {out }}$ & $\mathbf{K}$ & 1195 & 1082 & 1194 & 1192 \\
\hline$\overline{h_{1}}$ & $\mathrm{~W} /\left(\mathrm{m}^{2} \cdot \mathrm{K}\right)$ & 116 & 110 & 116 & 116 \\
\hline \multicolumn{6}{|c|}{ quartz windows 2 [inner] } \\
\hline$\varphi_{2 \mathrm{a}}^{\mathrm{rad}}$ & $\mathrm{kW} / \mathrm{m}^{2}$ & 5.63 & 4.38 & 1.58 & - \\
\hline$\varphi_{2 \mathrm{a}}^{\text {conv }}$ & $\mathrm{kW} / \mathrm{m}^{2}$ & -3.17 & -2.52 & -0.883 & - \\
\hline$\varphi_{2 \mathrm{a}}^{\text {cond }}$ & $\mathrm{kW} / \mathrm{m}^{2}$ & 2.46 & 1.86 & 0.701 & - \\
\hline$T_{2 \mathrm{a}}$ & $\mathrm{K}$ & 494 & 459 & 366 & - \\
\hline \multicolumn{6}{|c|}{ quartz windows 2 [outer] } \\
\hline$\varphi_{2 \mathrm{~b}}^{\mathrm{rad}}$ & $\mathrm{kW} / \mathrm{m}^{2}$ & 1.37 & 1.01 & 0.341 & - \\
\hline$\varphi_{2 \mathrm{~b}}^{\text {conv }}$ & $\mathrm{kW} / \mathrm{m}^{2}$ & 1.09 & 0.857 & 0.360 & - \\
\hline$T_{2 \mathrm{~b}}$ & $\mathrm{~K}$ & 429 & 405 & 346 & - \\
\hline
\end{tabular}

TABLE 3. Thermal energy balance of the combustion chamber thermal environment in Case 1 and impact of modeling choices. Case $1 \mathrm{~b}$ considers a constant thermal conductivity. Case 1c neglects radiative exchange between the quartz windows. Case $1 \mathrm{~d}$ considers the simplified model in Eq. (23).

quartz windows 2 equal to $2.46 \mathrm{~kW} / \mathrm{m}^{2}$. At the outer surface of the quartz windows 2 , this conductive flux is balanced with $56 \%$ in external radiative transfer and $44 \%$ with convective heat transfer with ambient air. The corresponding temperatures at the inner and outer surfaces are $494 \mathrm{~K}$ and $429 \mathrm{~K}$, respectively.

\section{SENSITIVITY ANALYSIS}

The impact and sensitivity of different parameters governing the observed energy balance is carried out in this section for case 1 .

First, the influence of the pressure housing steel temperature $T_{3}$ is studied. In order to quantify its impact on the predicted conductive flux at the first quartz windows $\varphi_{1}^{\text {cond }}$, the sensitiv- ity parameter $\alpha_{1}=\frac{T_{3}}{\varphi_{1}^{\text {cond }}} \frac{\mathrm{d} \varphi_{1}^{\text {cond }}}{\mathrm{d} T_{3}}$ is introduced. The evolution of this parameter with the stainless steel temperature $T_{3}$ is shown in Fig. 10(a). It is observed that for all considered temperatures, the global model is not very sensitive to the steel temperature $T_{3}$. Indeed, when the value of $T_{3}$ is increased by $1 \%$, the percentage of deviation of $\varphi_{1}^{\text {cond }}$ is lower than $0.03 \%$. This is due to (i) the small emitted radiative flux of the steel casing at a relatively cold temperature $T_{3}$ compared to $T_{\text {out }} \approx 1200 \mathrm{~K}$, hence $T_{\text {out }}^{4} \gg T_{3}^{4}$; and (ii) the smaller contribution (32\%) of the radiative flux in the total heat flux through the quartz windows 1 .

As for the pressure housing temperature sensitivity study, we introduce the parameter $\alpha_{2}=\frac{\overline{h_{1}}}{\varphi_{1}^{\text {cond }}} \frac{\mathrm{d} \varphi_{1}^{\text {cond }}}{\mathrm{d} \bar{h}_{1}}$ quantifying the impact of the heat transfer coefficient $\overline{h_{1}}$ on the predicted conductive flux $\varphi_{1}^{\text {cond }}$. The evolution of this sensitivity parameter as a function of the value of $\overline{h_{1}}$ is presented in Fig. 10(b). High sensitivity of the conductive flux $\varphi_{1}^{\text {cond }}$ with the value of $\overline{h_{1}}$ is observed. Indeed, for $\overline{h_{1}} \approx 100 \mathrm{~W} / \mathrm{m}^{2} / \mathrm{K}$, decreasing the value of $\overline{h_{1}}$ by $1 \%$, decreases the value of $\varphi_{1}^{\text {cond }}$ by approximatively $0.5 \%$. This can be explained by the linear dependency of the convective heat flux at the quartz windows 1 with the value of $\overline{h_{1}}$ and the fact that this flux represents $68 \%$ of the total flux at this outer window surface.

In order to study the impact of the thermal conductivity dependency on temperature prescribed by Eq. (20), a constant thermal conductivity, corresponding to its value at $293 \mathrm{~K}$ i.e. $k^{\text {slab }}=k^{0}=1.38 \mathrm{~W} / \mathrm{m} / \mathrm{K}$, is considered instead. Table 3 presents a comparison of the global energy balance obtained with a constant value of $k^{\text {slab }}$ (Case $1 \mathrm{~b}$ ) and the one obtained with the temperature dependency of the quartz thermal conductivity (Case 1). Case $1 \mathrm{~b}$ largely underestimates the conductive flux and the outer temperature of the combustion chamber quartz window. A detailed thermal conductivity description inside the quartz is then required in order to correctly estimate the conductive flux through the heated quartz material.

The influence of the distance $b$ separating the two quartz windows is studied with the parameter $\alpha_{3}=\frac{b}{\varphi_{1}^{\text {cond }}} \frac{\mathrm{d} \varphi_{1}^{\text {cond }}}{\mathrm{d} b}$. Figure 10(c) presents the evolution of the sensitivity of the predicted conductive flux with the quartz distance $b$. For low values of $b$, $\varphi_{1}^{\text {cond }}$ becomes sensitive to this distance because of the enhanced interaction between the quartz windows 1 and 2: for $b=20 \mathrm{~mm}$, increasing by $1 \%$ the value of $b$ decreases $\varphi_{1}^{\text {cond }}$ by $0.2 \%$. However, around the value encountered in the application $(b=108$ $\mathrm{mm}), \varphi_{1}^{\text {cond }}$ is weakly sensitive to the window distance $b$ : the quartz windows 1 mainly exchanges radiation with the stainless steel pressure housing for the actual value of $b$. To illustrate this, Table 3 presents a comparison of the global energy balance obtained considering no radiative exchanges between the two quartz windows $\left(F_{12}=F_{21}=0\right)$, denoted as Case $1 \mathrm{c}$, and the one obtained considering them (Case 1). As expected, results for quartz windows 1 temperature and fluxes are quasi similar to the ones obtained with detailed resolution. For the considered con- 


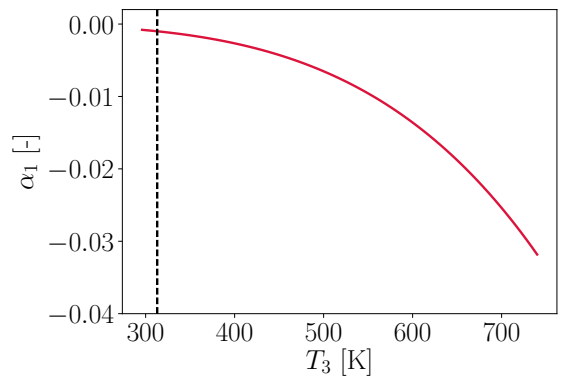

(a) Sensitivity to the temperature $T_{3}$

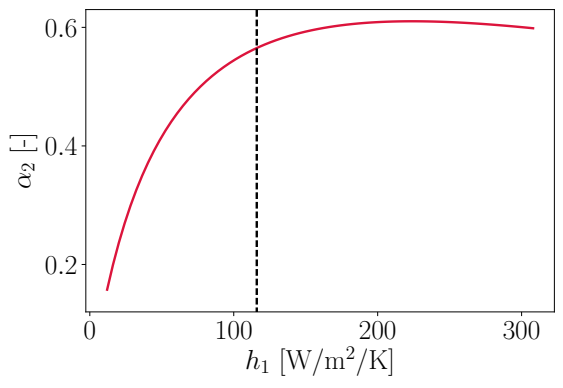

(b) Sensitivity to the heat transfer coefficient $\overline{h_{1}}$

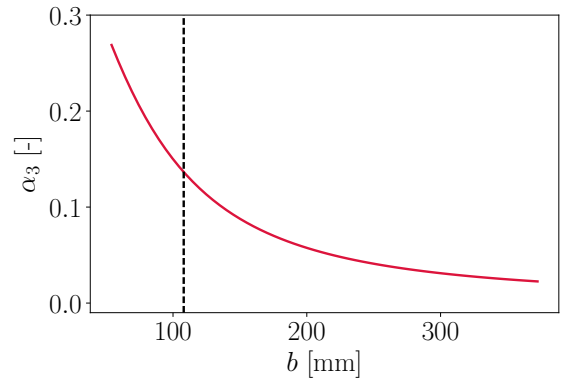

(c) Sensitivity to the distance $b$

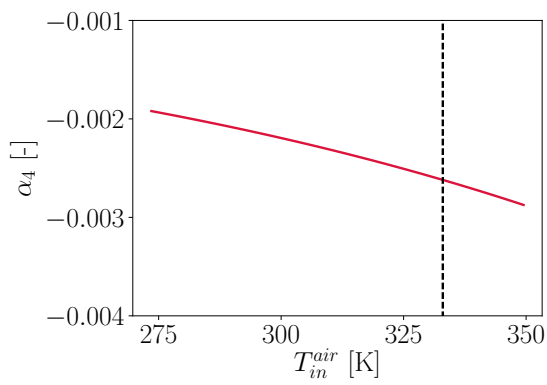

(d) Sensitivity to the temperature $T_{\mathrm{in}}^{\text {air }}$

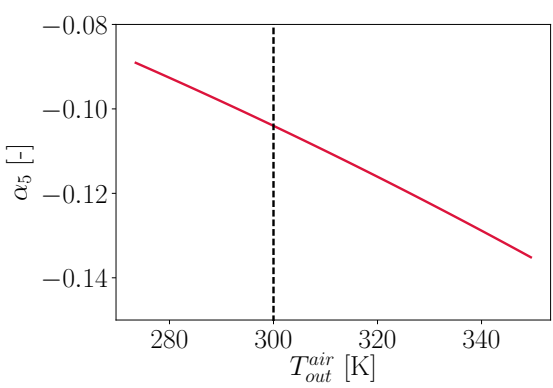

(e) Sensitivity to the temperature $T_{\text {out }}^{\text {air }}$

FIGURE 10. Sensitivity of the predicted conductive flux to the stainless steel temperature $T_{3}$ (a), the heat transfer coefficient $\overline{h_{1}}$ (b), the quartz separating distance $b(\mathrm{c})$, the temperature of air inside the pressure housing $T_{\text {in }}^{\text {air }}$ (d) and the external ambiant temperature $T_{\text {out }}^{\text {air }}$ (e). Black vertical dashed lines correspond to nominal values.

figuration, one can then neglect radiative interactions between these two windows in order to predict quartz windows 1 temperature. However, Case 1c with $F_{12}=F_{21}=0$ fails in retrieving the same temperature of the second quartz windows as for Case 1.

Finally, the influence of temperatures $T_{\text {in }}^{\text {air }}$ and $T_{\text {out }}^{\text {air }}$ are studied with the parameters $\alpha_{4}=\frac{T_{\text {in }}^{\text {air }}}{\varphi_{1}^{\text {cond }}} \frac{\mathrm{d} \varphi_{1}^{\text {cond }}}{\mathrm{d} T_{\text {in }}^{\text {air }}}$ and $\alpha_{5}=\frac{T_{\text {out }}^{\text {air }}}{\varphi_{1}^{\text {cond }}} \frac{\varphi_{1}^{\text {cond }}}{\mathrm{d} T_{\text {out }}^{\text {air }}}$. The evolutions of $\alpha_{4}$ and $\alpha_{5}$ are shown in Figs. 10(d) and 10(e), respectively. The predicted conductive flux is therefore not sensitive to the temperature $T_{\text {in }}^{\text {air }}$ (an increase of $0.1 \%$ in the temperature $T_{\text {in }}^{\text {air }}$ makes the conductive flux drop by $\approx 0.003 \%$ ), whereas it is slightly sensitive to the temperature $T_{\text {out }}^{\text {air }}$ (an increase by $1 \%$ in the temperature $T_{\text {out }}^{\text {air }}$ decreases by the conductive flux $0.1 \%$ ).

\section{RETAINED SIMPLIFIED EXTERNAL HEAT TRANSFER MODEL}

In the previous section, the sensitivity analysis has shown the strong influence of the convective transfer coefficient $\overline{h_{1}}$ and the negligible influence of the radiative interactions between the two quartz windows. Therefore, a simpler model for the external boundary condition, expressed here for a general inhomogeneous window temperature field, can be retained:

$$
\begin{aligned}
\varphi_{1}(x, z) & =\overline{A_{1}^{\text {slab }}}\left(T_{\text {out }}(x, z)\right) \sigma T_{\text {out }}(x, z)^{4}-\overline{A_{1}^{\text {slab }}}\left(T_{3}\right) \sigma T_{3}^{4} \\
& +h_{1}(x, z)\left(T_{\text {out }}(x, z)-T_{\text {in }}^{\text {air }}\right)
\end{aligned}
$$

where $T_{\text {out }}(x, z)$ corresponds to the temperature on the quartz combustion window's external face. This assumes that the quartz of the combustion chamber only exchanges radiative heat transfer with the stainless steel of the pressure housing (assumed isothermal at $T_{3}$ ), that radiation emitted from the quartz windows 1 does not modify the pressure housing thermal equilibrium, but also that the effect of multiple reflections between emitted radiative energy from quartz windows 1 and pressure housing's stainless steel can be neglected.

First, in order to quantify the impact of this simplification on the predicted fluxes, Table 3 presents a comparison of the predicted temperatures and fluxes at the quartz windows 1 between the complete (Case 1) and simplified (Case 1d) models. For the considered configuration, an error of approximatively 5 $\%$ on the radiative flux at the external face of the quartz windows 1 is obtained with the simplified model, leading to an error of approximatively $1 \%$ on the total conductive flux through the quartz windows 2 . Secondly, in order to assess the range of validity of 


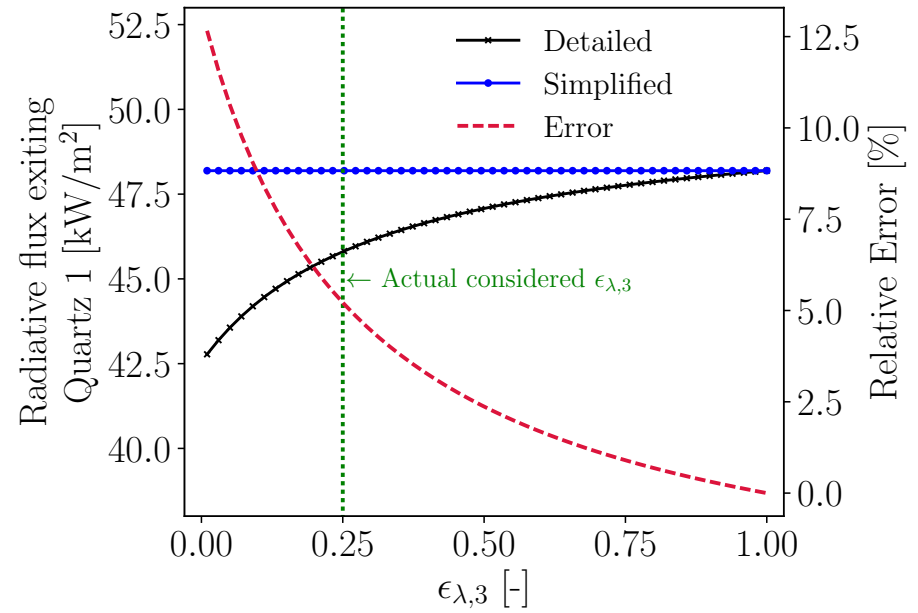

FIGURE 11. Evolution of error between complete and simplified models on radiative flux exiting quartz windows 1 as a function of stainless steel emissivity $\varepsilon_{\lambda, 3}$.

this simplification, Fig. 11 presents the radiatives fluxes at the outer surface of the combustion chamber quartz windows for the complete and simplified models, as a function of the stainless steel emissivity $\varepsilon_{\lambda, 3}$. These calculations have been carried out for Case 1. The relative error with the first version of the model decreases with the stainless steel emissivity and an error higher than $10 \%$ can be obtain for very low values of $\varepsilon_{\lambda, 3}$. In such a case, reflections between the quartz windows and the casing cannot be neglected anymore. For the actually considered stainless steel emissivity $\varepsilon_{\lambda, 3}=0.25$, the error between the complete and simplified model is approximatively $5 \%$ and can be considered as acceptable as the radiative flux only accounts for $30 \%$ of the total heat flux through the quartz windows 1 .

\section{CONCLUSION}

A model of external thermal environment in the considered DLR combustion chamber has been proposed: Nusselt number formulas are used to describe the window cooling system as an equivalent wall jet system and the free convection boundary layer on the internal and external faces of the quartz windows 2 ; the detailed description of the quartz windows spectral transmittance is combined with the view factor method to describe the radiative exchanges between the quartz windows and the pressure housing; A temperature-dependent expression of the quartz thermal conductivity is retained. The model satisfactorily retrieves the wall heat flux at the centerline of the combustion chamber quartz windows with an error of about $20 \%$ for the considered three operating points. This wall heat flux is estimated from the measured temperature profiles on both sides of the window. The corresponding experimental uncertainty in the wall heat flux is

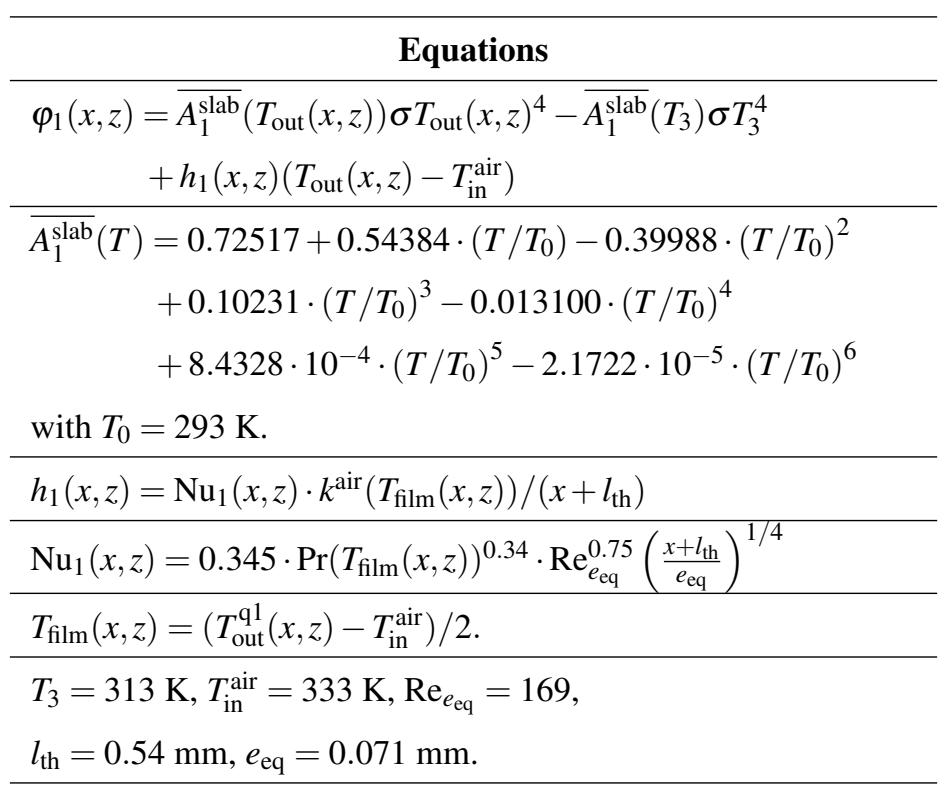

TABLE 4. Proposed simplified model of the thermal boundary condition of the combustion chamber quartz window's external surface.

roughly $27 \%$.

A sensitivity analysis was then carried out to understand the model's critical parameters and to derive a simplified version. The analysis revealed a high sensitivity to the heat transfer coefficient describing the wall jet cooling and to the thermal conductivity of the quartz windows while the impact of the distance separating the two sets of quartz windows remains small. A simplified version of the model given in Tab. 4 yields similar results while considering Planck-mean emissivities and radiative exchanges only with the stainless steel of the pressure housing. The semi-transparency of the viewing windows is denoted by the given temperature-dependency of the mean emissivity.

The local expressions in Tab. 4 are meant to be easily implemented into a conjugate heat transfer numerical study to solve for the temperature within the combustor windows. The large sensitivity on the jet cooling heat transfer coefficients invites to consider a separate CFD study of the cooling film for future investigations. Future work should also determine the impact of considering volume absorption within the quartz windows instead of retaining an opaque/transparent band radiative model. Finally, the complete model methodology can also benefit the preliminary design of combustor equipped with semi-transparent windows with or without pressure housing to evaluate wall heat transfer and (if present) the window cooling system efficiency.

\section{ACKNOWLEDGMENT}

This study is supported by the Air Liquide, CentraleSupelec and CNRS Chair on oxycombustion and heat transfer for energy 
and environment and by the OXYTEC project, and grant ANR12-CHIN-0001 of the French Agence Nationale de la Recherche. The authors also acknowledge the European project SOPRANO, Soot Processes and Radiation in Aeronautical innovative combustion, Horizon 2020 Grant Agreement No. 690724.

\section{REFERENCES}

[1] Higgins, B., McQuay, M. Q., Lacas, F., Rolon, J. C., Darabiha, N., and Candel, S., 2001. "Systematic measurements of oh chemiluminescence for fuel-lean, high-pressure, premixed, laminar flames". Fuel, 80(1), pp. 67-74.

[2] Tsurikov, M. S., Geigle, K. P., Krüger, V., SchneiderKühnle, Y., Stricker, W., Lückerath, R., Hadef, R., and Aigner, M., 2005. "Laser-based investigation of soot formation in laminar premixed flames at atmospheric and elevated pressures". Combustion Science and Technology, 177(10), 10, pp. 1835-1862.

[3] Malbois, P., Salaun, E., Frindt, F., Cabot, G., Renou, B., Grisch, F., Bouheraoua, L., Verdier, H., and Richard, S., 2017. Experimental investigation with optical diagnostics of a lean-premixed aero-engine injection system under relevant operating conditions. ASME Turbo Expo, Paper No. GT2017-64484, pp. V04BT04A022.

[4] Geigle, K. P., Hadef, R., and Meier, W., 2014. "Soot formation and flame characterization of an aero-engine model combustor burning ethylene at elevated pressure". Journal of Engineering for Gas Turbines and Power, 136(2), 10, pp. 021505-021505.

[5] Heraeus. Quartz glass for optics data and properties.

[6] Eberle, C., Gerlinger, P. M., Geigle, K. P., and Aigner, M., 2014. "Soot predictions in an aero-engine model combustor at elevated pressure using urans and finite-rate chemistry". 50th AIAA/ASME/SAE/ASEE Joint Propulsion Conference, AIAA Propulsion and Energy Forum, 3472, pp. 1-14.

[7] Franzelli, B., Riber, E., Cuenot, B., and Ihme, M., 2015. Numerical modeling of soot production in aero-engine combustors using large eddy simulations. ASME Turbo Expo, Paper No. GT2015-43630, pp. V04BT04A049.

[8] Eberle, C., Gerlinger, P., Geigle, K. P., and Aigner, M., 2015. "Numerical investigation of transient soot evolution processes in an aero-engine model combustor". Combustion Science and Technology, 187(12), pp. 1841-1866.

[9] Koo, H., Raman, V., Mueller, M. E., and Geigle, K.-P., 2016. "Les of a sooting flame in a pressurized swirl combustor". 54th AIAA Aerospace Sciences Meeting, AIAA SciTech Forum, 2123, pp. 1-9.

[10] Wick, A., Priesack, F., and Pitsch, H., 2017. Large-eddy simulation and detailed modeling of soot evolution in a model aero engine combustor. ASME Turbo Expo, Paper No. GT2017-63293, pp. V04AT04A020.

[11] Nogenmyr, K. J., Cao, H. J., Chan, C. K., and Cheng,
R. K., 2013. "Effects of confinement on premixed turbulent swirling flame using large eddy simulation". Combustion Theory and Modelling, 17(6), 12, pp. 1003-1019.

[12] Guiberti, T. F., Durox, D., Scouflaire, P., and Schuller, T., 2015. "Impact of heat loss and hydrogen enrichment on the shape of confined swirling flames". Proceedings of the Combustion Institute, 35(2), pp. 1385-1392.

[13] Tay-Wo-Chong, L., Zellhuber, M., Komarek, T., Im, H. G., and Polifke, W., 2016. "Combined influence of strain and heat loss on turbulent premixed flame stabilization". Flow, Turbulence and Combustion, 97(1), pp. 263-294.

[14] Mercier, R., Guiberti, T. F., Chatelier, A., Durox, D., Gicquel, O., Darabiha, N., Schuller, T., and Fiorina, B., 2016. "Experimental and numerical investigation of the influence of thermal boundary conditions on premixed swirling flame stabilization". Combustion and Flame, 171(Supplement C), pp. 42-58.

[15] Ihme, M., and Pitsch, H., 2008. "Modeling of radiation and nitric oxide formation in turbulent nonpremixed flames using a flamelet/progress variable formulation". Physics of Fluids, 20(5).

[16] Lamouroux, J., Ihme, M., Fiorina, B., and Gicquel, O., 2014. "Tabulated chemistry approach for diluted combustion regimes with internal recirculation and heat losses". Combustion and Flame, 161(8), 8, pp. 2120-2136.

[17] Jaure, S., Duchaine, F., Staffelbach, G., and Gicquel, L., 2013. "Massively parallel conjugate heat transfer methods relying on large eddy simulation applied to an aeronautical combustor". Computational Science \& Discovery, 6(1), p. 015008 .

[18] Mari, R., Cuenot, B., Rocchi, J.-P., Selle, L., and Duchaine, F., 2016. "Effect of pressure on hydrogen/oxygen coupled flame-wall interaction". Combustion and Flame, 168, 6, pp. 409-419.

[19] Miguel-Brebion, M., Mejia, D., Xavier, P., Duchaine, F., Bedat, B., Selle, L., and Poinsot, T., 2016. "Joint experimental and numerical study of the influence of flame holder temperature on the stabilization of a laminar methane flame on a cylinder". Combustion and Flame, 172(Supplement C), pp. 153-161.

[20] Jones, W. P., and Paul, M. C., 2005. "Combination of dom with les in a gas turbine combustor". International Journal of Engineering Science, 43(5-6), 3, pp. 379-397.

[21] Gonçalves dos Santos, R., Lecanu, M., Ducruix, S., Gicquel, O., Iacona, E., and Veynante, D., 2008. "Coupled large eddy simulations of turbulent combustion and radiative heat transfer". Combustion and Flame, 152(3), 2, pp. 387-400.

[22] Poitou, D., Amaya, J., El Hafi, M., and Cuenot, B., 2012. "Analysis of the interaction between turbulent combustion and thermal radiation using unsteady coupled les/dom simulations". Combustion and Flame, 159(4), 4, pp. 1605- 
1618.

[23] Berger, S., Richard, S., Duchaine, F., Staffelbach, G., and Gicquel, L. Y. M., 2016. "On the sensitivity of a helicopter combustor wall temperature to convective and radiative thermal loads". Applied Thermal Engineering, 103, 6, pp. 1450-1459.

[24] Koren, C., Vicquelin, R., and Gicquel, O., 2017. Highfidelity multiphysics simulation of a confined premixed swirling flame combining large-eddy simulation, wall heat conduction and radiative energy transfer. ASME Turbo Expo, Paper No. GT2017-64844, pp. V05CT17A010.

[25] Modest, M. F., and Haworth, D. C., 2016. Radiative Heat Transfer in Turbulent Combustion Systems. Springer.

[26] Zhao, X. Y., Haworth, D. C., Ren, T., and Modest, M. F., 2013. "A transported probability density function/photon Monte Carlo method for high-temperature oxynatural gas combustion with spectral gas and wall radiation". Combustion, Theory and Modelling, 17(2), pp. 354-381.

[27] Poitou, D., El Hafi, M., and Cuenot, B., 2011. "Analysis of radiation modeling for turbulent combustion: Development of a methodology to couple turbulent combustion and radiative heat transfer in les". Journal of Heat Transfer, 133(6), 03, pp. 062701-062701.

[28] Nau, P., Yin, Z., Geigle, K. P., and Meier, W., 2017. "Wall temperature measurements at high pressures and temperatures in sooting flames in a gas turbine model combustor". Applied Physics B, 123(12), p. 279.

[29] Green, D., and Perry, R., 2007. Perry's Chemical Engineers' Handbook, Eighth Edition. McGraw Hill professional. McGraw-Hill Education.

[30] ISF. International sooting flame workshop, http://www.adelaide.edu.au/cet/isfworkshop/data-sets/, accessed 24/10/2017.

[31] Glauert, M. B., 1956. “The wall jet”. Journal of Fluid Mechanics, 1(6), pp. 625-643.

[32] Schwarz, W. H., and Caswell, B., 1961. "Some heat transfer characteristics of the two-dimensional laminar incompressible wall jet". Chemical Engineering Science, 16(3), pp. 338-351.

[33] Issa, J., and Ortega, A., 2004. "Numerical computation of the heat transfer and fluid mechanics in the laminar wall jet and comparison to the self-similar solutions". ASME International Mechanical Engineering Congress and Exposition(61701), pp. 191-197.

[34] Issa, J. S., 2006. "Scaling of convective heat transfer in laminar and turbulent wall jets with effects of freestream flow and forcing". PhD thesis, The University of Arizona.

[35] Churchill, S. W., and Chu, H. H. S., 1975. "Correlating equations for laminar and turbulent free convection from a vertical plate". International Journal of Heat and Mass Transfer, 18(11), pp. 1323-1329.

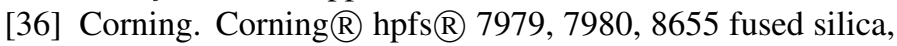

optical materials product information.

[37] Modest, M. F., 2013. Radiative Heat Transfer (Third Edition). Academic Press, Boston.

[38] Howell, J., Menguc, M., and Siegel, R., 2010. Thermal Radiation Heat Transfer, 5th Edition. Taylor \& Francis.

[39] Combis, P., Cormont, P., Gallais, L., Hebert, D., Robin, L., and Rullier, J.-L., 2012. "Evaluation of the fused silica thermal conductivity by comparing infrared thermometry measurements with two-dimensional simulations". Applied Physics Letters, 101(21), p. 211908. 